\title{
Effect of immediate pain management on oxygenation level among early extubation patients post heart surgery
}

Mona Sayed Elgazar, Inshrah Roshdy Mohammed, Yasser Shaban Mubarak, Marwa M. Abdelbaky,

(1) Clinical instructor at the medical surgical department, Minia University, Egypt.

(2) Assistant professor at the medical surgical department, Faculty of Nursing, Minia University, Egypt

(3) Assistant profesior at the cardiothoracic surgery department, Faculty of Medicin, Minia University, Egypt

(4) Lecturer at the medical surgical department (critical care nursing), Faculty of Nursing, Minia University, Egypt

\begin{abstract}
Pain is the most severe in patients after open thoracic surgery. Patients undergoing surgery report slightly higher pain intensity than other surgery types. The aim of the study: is to evaluate the effect of immediate pain management on oxygenation levels among early extubated patients post-heart surgery. Subjects and Methods: Quasi-experimental design; a sample of 60 patients (male and female) divided equally into two groups; study group ( $\mathrm{n}=30$ ) and control group $(\mathrm{n}=30)$. Setting: cardiothoracic ICU and cardiothoracic department at the cardiothoracic hospital that belongs to Minia University Hospitals, Egypt. Tools: Three tools: I: Socio-demographic and medical Assessment, II: oxygenation level assessment and III: Numeric Pain Scale. Results: Mean age of study and control groups were $(38.4 \pm 5.4) \&(37.2 \pm 4.8)$ year respectively. (40\%) from the study group suffered a myocardial infarction and did coronary angioplasty, (43.3\%) of the control suffered coronary artery stenosis $(33.3 \%)$ among them did coronary angioplasty. Related to the pain scale there was a significant difference between study and control groups at p-value $<0.05$. Also regarding oxygenation level which presented by a significant difference between both groups about breathing sound and arterial blood gases test at $1^{\text {st }}, 3^{\text {rd }}$ and $7^{\text {th }}$ day of the study, presented by $p$-value $<0.05$. Conclusion: This study concluded that pain management has a positive effect on a patient's oxygenation level which was presented in improving patients breathing sound and arterial blood gases which reflected on the patient's outcomes post-cardiac surgery. Recommendations: All cardiac surgery patients should receive pain management strategies before their operations and the pain management strategies should be included in the protocol of care for cardiothoracic patients.
\end{abstract}

Keywords: Pain, oxygenation, extubated, heart \& surgery

\section{Introduction}

Cardiac surgery is one of the most important procedures that can resolve many cardiac problems. The most important of which are myocardial revascularization, valve repair or replacement, repair of congenital or acquired structural abnormalities, placement of a mechanical assist device, and heart transplantation (Gunay, etal. 2016). The post-operative phase is the most critical period for cardiac patients, which may result in many complications as pulmonary, cardiovascular, neurological, and renal, that prolong hospitalization, increase costs and have a direct effect on survival (Nair, S., \& Kazi, A. 2019)).

In prospective studies of Egyptian patients after open-heart surgery, $86 \%$ of the patients had postoperative complications with morbidity and mortality rates of $23 \%$ and $1.7 \%$ respectively (WHO, 2108). Coronary artery bypass grafting (CABG) and heart valve surgery are the most commonly performed procedures in cardiac surgery worldwide. The further development of surgical skills and technical settings enables complex surgery in increasingly old and morbid patients with poor left ventricular function and a multitude of comorbidities. To minimize as far as possible the pain experienced by cardiac surgery patients, surgical procedures should be performed using minimally invasive techniques. Minimally invasive surgery has grown in popularity, and the potential benefits of reducing surgical trauma include decreased postoperative bleeding, reduced incidence of sternal wound infections, and shortened recovery period after surgery (Oshvandi, K., et al 2020).

The majority of possible complications may be resolved by early activity in the early postoperative period.
As early weaning is accompanied by early pain management, which in turn reduce post-cardiac surgery pulmonary complications (Patman, S., 2019). Each surgical intervention is associated with the patient's perception of pain. Postoperative pain is due to intraoperative damage to tissues/organs, and its intensity and extent are generally proportional to the extent of the surgery. In cases of a large trauma, in addition to superficial and deep somatic pain, the visceral component of postoperative pain is also involved, triggered both by smooth-muscle contraction, caused by compression and tension of the visceral structures and by inflammatory lesions (Xavier, G., et al 2019).

Pain is the most severe in patients after open thoracic surgery. Patients undergoing surgery with the use of cardiopulmonary bypass report slightly higher pain intensity than those in whom extracorporeal circulation is not used. Extracorporeal circulation is essentially associated with the induction of the systemic inflammatory response syndrome, with potential end-organ dysfunctions. It has been shown that women after cardiac surgery report higher pain intensity and a significantly higher number of pain areas than men, and that elderly patient have a higher pain threshold (Yazdannik, A., etal.2016).

Moreover, persistent pain after cardiac surgery may lead to pulmonary dysfunction, decreased oxygenation mainly due to difficulty in coughing. Pain during movement prevents patients from mobilization, breathing exercises, and rehabilitationEventually, uncontrolled pain after surgery may result in slower rehabilitation, longer intensive care unit and hospital stays, more readmissions, higher long-term (Bjørnnes AK, et al., 2016) 
The critical care nurse has a vital role in the postoperative care of cardiac patients. The nurse is mostly responsible for monitoring and assessing the cardiovascular, respiratory, and renal status to create an effective care plan. Also in planning and implementing effective pain management strategies to control the pain post-operatively (Zanini, M.,etal., 2006).

\section{Significance of the study}

By 2030, nearly 23.6 million people will pass away from cardiovascular diseases. This incidence gives rise to 17.9 million deaths (32.1\%) in 2015. Deaths at a given age from CVD are more common and are increasing in much of the developing world, while rates have declined in most of the developed world since the 1970s. Arteria coronaria disease and stroke account for $80 \%$ of CVD deaths in males and $75 \%$ of CVD deaths in females.

The absence of immediate pain management leads to many complications as delayed extubation, increase the rate of pulmonary infection, atelectasis, and prolonged stay in ICU.So effective pain management will help patients to maintain their oxygenation level and hemodynamic stability which will reduce hospital stay and treatment cost. Thus I will perform this study to evaluate the effect of pain management on oxygenation level and pulmonary function among early extubation patients following cardiothoracic surgery (Azevedo et al., 2016).

My experience in the cardiothoracic surgery unit as a nursing staff member for ten years ago found target patients who had done cardiac surgery and did not receive effective pain management remain one factor leads to of high rate of pain-related complications as regarded to units record

\section{Subjects and methods \\ Aim of the Study}

The present study aims to evaluate the effect of immediate pain management on oxygenation level among early extubated patient post heart surgery

\section{Hypothesis}

Pain management strategies will improve oxygenation levels among early extubated patients post heart surgery?

\section{Research Design}

Quasi-experimental research design (study \& control study) was utilized to fulfill the purpose of this study

\section{Subjects}

The study included convenient adult patients undergoing elective heart surgery selection at the cardiothoracic surgery unit during the conducting of the study. Patients enrolled in the study classified equally into two groups (study and control groups).

Both groups of the current study were selected according to the following inclusion and exclusion criteria:

\section{Inclusive Criteria:}

(1) Conscious extubated patients who will be able to practice chest physiotherapy.

(2) Patient with valvular replacement.

(3) Patient with Coronary Artery Bypass Grafting (CABG).
Exclusive Criteria: Patients will be excluded if:

(1) Chronic obstructed pulmonary disease (COPD).

(2) Diabetic patient.

(3) Congenital anomalies in the heart.

(4) Upper and lower respiratory infection.

\section{Setting}

The current study was carried out at the cardiothoracic ICU and cardiothoracic surgery departments at the cardiothoracic hospital that belongs to Minia University Hospitals. The cardiothoracic surgery department consists of 4 rooms with 16 beds, and the cardiothoracic intensive care unit (CICU), which contains 8 beds.

\section{Study Duration:}

The study data collections were collected over a period of eight months, starting from July 2018 to February 2019.

\section{Tools of Data Collection}

The current study data were collected by using three tools. The content of the tools was established after an extensive literature review. Such as (Brunner and Suddarth's Textbook of medical\& surgical nursing (2018), Critical Care Nursing Books (2011), Morton etal a holistic approach (2018) and the online researches that related to the current study.

\section{First Tool: Socio-demographic and medical Assessment} sheet:

- Is an interview assessment sheet, was developed by the researcher and it was included two parts.

- 1st part covers socio-demographic data of the patient as age, gender, marital status.

- $2^{\text {nd }}$ part covers medical data as medical diagnosis, type of cardiac surgery, presence of any chronic disease........ etc.

\section{Second Tool: oxygenation level assessment sheet:}

It was developed and collected by the researcher for the studied subjects following cardiothoracic surgery and after their extubation to assess their patients' oxygenation level, this assessment was collected through the following three parts.

- $\quad 1^{\text {st }}$ part: Mechanical Ventilation parameter: It will be collected before the removal of the patient's ETT according to the cardiothoracic unit policy. It includes seven items, friction of inspired oxygen, tidal volume......etc'.

- $2^{\text {nd }}$ part: specific Respiratory system assessment as Tracheal Secretions characteristics and breath sound. this part was assessed three times during the first week $\left(1^{\text {st }}, 3^{\text {rd }}\right.$ and $7^{\text {th }}$ days $)$ after the patient's extubation.

- $3^{\text {rd }}$ part: laboratory Investigation findings as Arterial Blood Gases test (ABGs) to assess patient's oxygenation level $\left(\mathrm{PH}, \mathrm{PaO}_{2}, \mathrm{PaCO}_{2}, \mathrm{HCO}_{3}, \mathrm{SaO}_{2}\right)$ it was assessed three times per day (once per nursing shift). And the researcher has recorded all the ABGs findings for study subjects who extubated to estimate its mean average.

\section{Third Tool: Numeric Pain Scale}

It was developed by (McCaffery, M., Beebe, A., et al. 1989). it was ranked from zero to ten. The patient who got a zero mark means no pain sensation but who was get ten 
marks means he had the worst pain imaginable. It was assessed twice per nursing shift through the $1^{\text {st }}$ three days for patients after their extubation.

Preoperative education for patients undergoing open-heart surgery regarding specific non-pharmacological pain management strategies. It was prepared by the researcher after reviewing extensive literature, it includes specific practices as following

(1) Positioning (high fowler's position, semi fowler's position)

(2) Relaxation technique measures.

(3) Turning and moving practices.

\section{Tools validity and Reliability}

The tool's content was examined by a panel of five experts, four in the field of Medical-Surgical Nursing Department at Faculty of Nursing Minia university and one cardiologists from the cardiothoracic unit. The three tools were tested for content reliability using Cronbach's alpha test it was (0.94).

\section{Pilot Study}

A pilot study was carried out on $10 \%$ (6 patients) of the total sample to test feasibility, objectivity, and applicability of the data collection tools. The pilot study sample was not included in the study sample because the study tools were needed more modification.

\section{Ethical Consideration}

Official permission to conduct the study was obtained from the ethical committee of the Faculty of Nursing, Dean of the Faculty of Nursing, Minia University, Hospital's Director, and agreement from Egypt academic for research center and technology. subject's participation in this study has voluntarily participated, oral consent was obtained from the patients and the researcher informed about the purpose, procedure, benefits, nature of the study, follow up, and he /she has the right to withdraw from the study at any time without any rationale. Confidentiality and anonymity of each subject were ensured through coding of all data and protecting the obtained data.

\section{Study procedure \\ Preparatory phase}

The current study was conducted by preparing the different data collection tools, in addition to obtaining oral agreements from the study subjects who were scheduled for cardiac surgery by the investigator about the purpose and nature of the study.

\section{Implementation phase}

The implementation of the study for patients (both groups) was stated during their preoperative period to identify the patient who met inclusion and exclusion criteria. The three study tools were collected from the control group firstly by the researcher then they were started to collect study group through following steps, the first step was an initial assessment by using the first tool, after that, the preoperative educational sessions for patients about specific pain management strategies through demonstration by researcher and re-demonstration by patients until their performance was accepted. All these pain management measures were formulated by a researcher in an educational brochure was given to the patients to remember them about these practices training preoperatively. The brochure was offered in the Arabic language and it included clear instruction about steps of practices, frequency and supported by photo. Teaching sessions for patients were taken from 3-4 sessions for one week preoperatively. The duration of each session for the study group was ranged from 20 to 30 minutes.

\section{Evaluation phase}

The study tools collected from both groups (study and control) were evaluated according to schedule measurements that were previously mentioned in the study tools description.

\section{Statistical analysis of data}

Data were summarized, tabulated, and presented using descriptive statistics in the form of frequency distribution, percentages, means, and standard deviations as a measure of dispersion. A statistical package for the social science (SPSS), version (20) was used for statistical analysis of the data, as it contains the test of significance given in standard statistical books. Numerical data were expressed as mean and SD. Qualitative data were expressed as frequency and percentage. Probability (P-value) is the degree of significance, less than 0.05 was considered significant. The smaller the P-value obtained, the more significant is the result $\left.{ }^{*}\right)$, less than 0.001 was considered highly significant $(* *)$, and the correlation coefficient was done by using the Pearson correlation test. ANOVA test was used to compare two different means among study and control group in the current study

Result

Table (1): Distribution of studied subjects (study and control groups) according to their socio-demographic data (N= $\mathbf{7})$

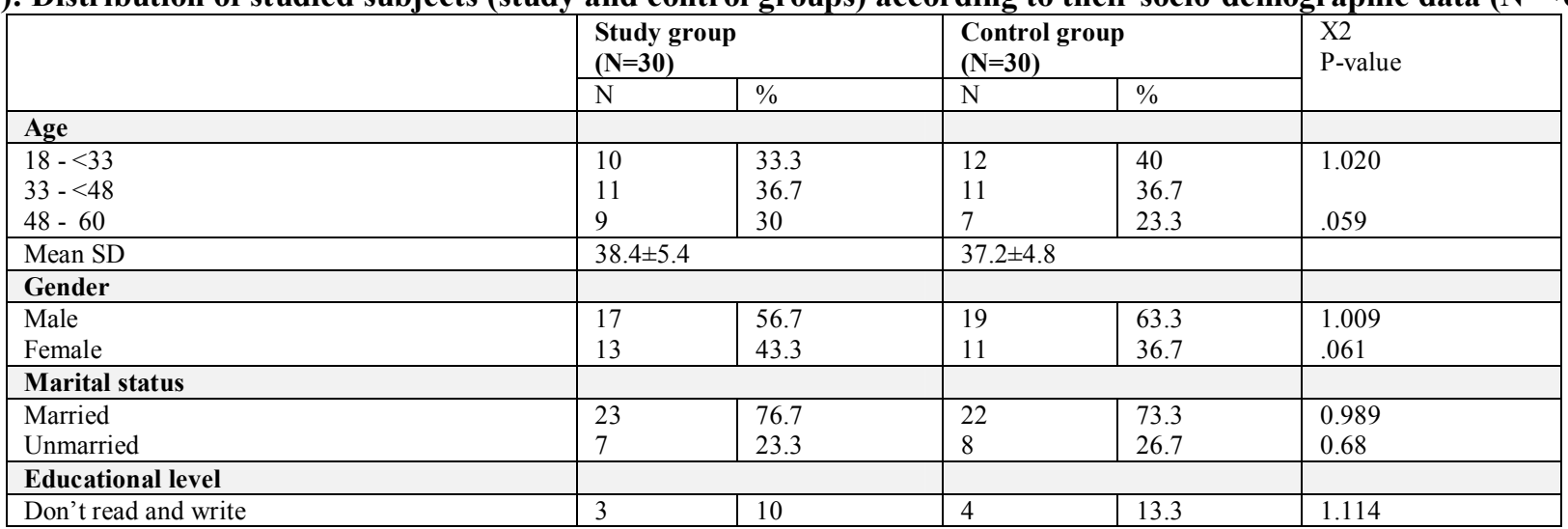


Minia Scientific Nursing Journal (Print - ISSN 2537-012X) (Online - ISSN 2785-9797) Vol. (8) No. (1) December 2020

\begin{tabular}{|c|c|c|c|c|c|}
\hline & \multicolumn{2}{|c|}{$\begin{array}{l}\text { Study group } \\
(\mathrm{N}=\mathbf{3 0})\end{array}$} & \multicolumn{2}{|c|}{$\begin{array}{l}\text { Control group } \\
(\mathrm{N}=30)\end{array}$} & \multirow[t]{2}{*}{$\begin{array}{l}\mathrm{X} 2 \\
\mathrm{P} \text {-value }\end{array}$} \\
\hline & $\mathrm{N}$ & $\%$ & $\mathrm{~N}$ & $\%$ & \\
\hline Read and write & 5 & 16.7 & 8 & 26.7 & \\
\hline Preparatory & 11 & 36.7 & 10 & 33.3 & .056 \\
\hline Secondary & 7 & 23.3 & 5 & 16.7 & \\
\hline University & 4 & 13.3 & 3 & 10 & \\
\hline \multicolumn{6}{|l|}{ Residence } \\
\hline Rural & 20 & 66.9 & 19 & 63.3 & 1.205 \\
\hline Urban & 10 & 33.3 & 11 & 36.7 & .051 \\
\hline \multicolumn{6}{|l|}{ Occupation } \\
\hline Owner of a craft & 7 & 23.3 & 9 & 30 & 1.077 \\
\hline Farmer & 9 & 30 & 8 & 26.7 & \\
\hline Employer & 12 & 40 & 9 & 30 & .055 \\
\hline does not work & 2 & 6.6 & 4 & 13.3 & \\
\hline
\end{tabular}

Table (1): showed that the mean average age of the study group was (38.4 \pm 5.4$)$ year and in the control group was (37.2 \pm 4.8$)$ year. As regard to gender and marital status, $(56.7 \%$ and $76.7 \%)$ respectively among the study group were male and married, nearly similar to the control group, $(63.3 \%$ and $73.3 \%)$ respectively. Concerning the educational level, it was found that $(36.7 \%)$ of the study group and (33.3\%) of the control had preparatory education. Moreover, $(66.7 \%)$ of the study group and (63.3\%) of the control were lived in rural areas. Finally, the occupational level, $(40 \%)$ of the study group and (30\%) of the control were an employer.

Table (2): Distribution of studied subjects (study and control group) according to their medical data (N= 0 ).

\begin{tabular}{|c|c|c|c|c|c|}
\hline & \multicolumn{2}{|c|}{$\begin{array}{l}\text { Study group } \\
(\mathrm{N}=30)\end{array}$} & \multicolumn{2}{|c|}{$\begin{array}{l}\text { Control group } \\
(\mathrm{N}=30)\end{array}$} & \multirow[t]{2}{*}{$\begin{array}{l}\mathrm{X}^{2} \\
\mathrm{P} \text {-value }\end{array}$} \\
\hline & $\mathbf{N}$ & $\%$ & $\mathbf{N}$ & $\%$ & \\
\hline \multicolumn{6}{|l|}{ Medical diagnosis } \\
\hline Myocardial infarction & 12 & 40 & 10 & 33.3 & 1.110 \\
\hline Mitral valve stenosis & 8 & 26.7 & 7 & 23.4 & \\
\hline Coronary artery stenosis & 10 & 33.3 & 13 & 43.3 & .060 \\
\hline \multicolumn{6}{|l|}{ Type of cardiac surgery } \\
\hline Coronary Angioplasty & 12 & 40 & 10 & 33.3 & 1.300 \\
\hline Mitral valve replacement & 8 & 26.7 & 7 & 23.4 & \\
\hline Coronary artery bypass graft & 6 & 20 & 8 & 26.7 & .051 \\
\hline Stent placement & 4 & 13.3 & 5 & 16.6 & \\
\hline \multicolumn{6}{|c|}{ Risk factor *select more answer } \\
\hline Smoking & 6 & 20 & 9 & 30 & 1.998 \\
\hline Physical inactivity & 14 & 46.6 & 10 & 33.3 & \\
\hline High blood pressure & 9 & 30 & 13 & 43.3 & $.049 *$ \\
\hline Obesity & 7 & 23.4 & 8 & 26.7 & \\
\hline \multicolumn{6}{|l|}{ Chronic disease } \\
\hline Yes & 27 & 90 & 26 & 86.7 & 0.997 \\
\hline No & 3 & 10 & 4 & 13.3 & .062 \\
\hline \multicolumn{6}{|l|}{ Past cardiothoracic surgery } \\
\hline Yes & 7 & 23.4 & 3 & 10 & 2.001 \\
\hline No & 23 & 76.6 & 27 & 90 & $.041 *$ \\
\hline \multicolumn{6}{|l|}{ Past hospitalization } \\
\hline Yes & 19 & 63.3 & 17 & 56.7 & 1.004 \\
\hline No & 11 & 36.7 & 13 & 43.3 & .057 \\
\hline
\end{tabular}

Table (2) presented that, (40\%) of the study group suffered from myocardial infarction and they did coronary angioplasty surgery, similar to $(43.3 \%)$ of the control group suffered from coronary artery stenosis but only (33.3\%) among them were did coronary angioplasty. $(20 \& 46.6 \%)$ respectively of the study group were had a risk factor of smoking and physical inactivity. And ( $30 \& 33.3 \%)$ of the control group had the same risk factors. Also, $(90 \%) \&(86.7 \%)$ among both groups were suffered from chronic disease. Moreover, (76.6 \& 90\%) from the study and control group respectively were didn't have a history of cardiothoracic surgery and were not hospitalized previously and the highest percentage from both groups $(63.3 \& 56.7 \%)$ respectively were admitted previously to the hospital

Table (3) Distribution of mean average scores of mechanical ventilator parameter for studies groups before their extubation $(\mathbf{N} .=60)$

\begin{tabular}{|l|l|l|l|l|}
\hline & $\begin{array}{l}\text { Mean score of } \\
\text { Study group }\end{array}$ & $\begin{array}{l}\text { Mean score of } \\
\text { Control group }\end{array}$ & P-value \\
\hline Tidal volume & $451.6 \pm 72.84$ & $448.6 \pm 71.7$ & 1.008 & .056 \\
\hline Fio2 & $0.44 \pm 0.15$ & $0.48 \pm 0.18$ & 1.103 & .051 \\
\hline Rate & $16.3 \pm 2.05$ & $17.2 \pm 2.11$ & 1.019 & .054 \\
\hline PEEP & $7.86 \pm 1.67$ & $8.14 \pm 1.57$ & 0.986 & .063 \\
\hline PS & $13.10 \pm 2.0$ & $14.15 \pm 3.3$ & 1.030 & .053 \\
\hline ETT size & $8.4 \pm 0.46$ & $8.5 \pm 0.94$ & 0.938 & .052 \\
\hline Cuff pressure & $18.69 \pm 3.9$ & $18.86 \pm 4.8$ & 0.763 \\
\hline
\end{tabular}

N.B. the mechanical ventilator parameters were assessed once before extubation 
Table (3) shows that there was no statistical significance difference between both groups of the study (study \& control groups) regarding the $7^{\text {th }}$ item of mechanical ventilator parameters.

Table (4) Comparison between (study and control group) related Pain score through the first seven days post their extubation.

\begin{tabular}{|l|l|l|l|l|}
\hline & $\begin{array}{l}\text { Mean of } \\
\text { Study group } \\
(\mathrm{N}=30)\end{array}$ & $\begin{array}{l}\text { Mean of } \\
\text { Control group } \\
(\mathrm{N}=30)\end{array}$ & X2 & P-value \\
\hline 3rd day & $5.76 \pm 1.18$ & $7.01 \pm 1.88$ & 3.462 & $.020^{*}$ \\
\hline 5th day & $4.14 \pm 1.11$ & $6.60 \pm 2.10$ & 2.938 & $.025^{*}$ \\
\hline 7th day & $2.23 \pm 0.98$ & $4.42 \pm 1.50$ & 3.012 & $.021^{*}$ \\
\hline
\end{tabular}

Table (4) showed that, that the Mean SD score related pain score post extubated of a study group at $3^{\text {rd }}$ day was $5.76 \pm 1.18$, while the control group was $7.01 \pm 1.88$. On the $5^{\text {th }}$ day, the mean score of the study group was $4.14 \pm 1.11$, while the control group was $6.60 \pm 2.10$. While at $7^{\text {th }}$ day, the mean score of the study group was $2.23 \pm 0.98$, while the control group was $4.42 \pm 1.50$. Also, this table detected that there was a significant difference between the control and study groups related to pain scores at $\mathrm{p}$-value $<0.05$.

Table (5) comparison between frequency distribution of the study and control groups according to their breathing sound through the first seven days post their extubation.

\begin{tabular}{|c|c|c|c|c|c|c|c|}
\hline & \multicolumn{3}{|c|}{$\begin{array}{l}\text { Study group } \\
(\mathrm{N}=30)\end{array}$} & \multicolumn{3}{|c|}{$\begin{array}{l}\text { Control group } \\
(\mathrm{N}=30)\end{array}$} & \multirow[t]{3}{*}{$\begin{array}{l}\mathrm{X}^{2} \\
\text { P-value }\end{array}$} \\
\hline & Normal & Crackles & Wheeze & Normal & Crackles & Wheeze & \\
\hline & N (\%) & N (\%) & N (\%) & $\mathrm{N} \quad(\%)$ & N (\%) & N (\%) & \\
\hline $1^{\text {st }}$ day & $22(73.3)$ & $7(23.3)$ & $1(3.3)$ & $16(53.3)$ & $10(33.3)$ & $4(13.4)$ & $\begin{array}{l}2.088 \\
.043^{*} \\
\end{array}$ \\
\hline $3^{\text {rd }}$ day & $17(56.6)$ & $11(36.7)$ & $2(6.7)$ & $10(33.3)$ & $14(46.7)$ & $6(20)$ & $\begin{array}{l}2.263 \\
.040^{*}\end{array}$ \\
\hline $7^{\text {th }}$ day & $19(63.3)$ & $10(33.3)$ & $1(3.3)$ & $12(40)$ & $11(36.7)$ & $7(23.3)$ & $\begin{array}{l}3.038 \\
.036^{*}\end{array}$ \\
\hline
\end{tabular}

Table (5) revealed that $(73.3 \%)$ of the study group had normal sound on $1^{\text {st }}$ day, while $(53.3 \%)$ of the control group had normal sound. Also, only $(3.3 \%)$ of the study group had wheeze on the $7^{\text {th }}$ day, while $(23.3)$ of the control group had the same sound on the same day of the study. Also, this table revealed that there was a significant difference between the study and control group related to breathing sound at the $1^{\text {st }}$ day, $3^{\text {rd }}$ day and $7^{\text {th }}$ day presented by p-value $(.043, .040 \& .036)$ at the $1^{\text {st }}$-week post-extubation.

Table (6) Comparison between (study and control group) related to arterial blood gases value through the first seven days post their extubation.

\begin{tabular}{|c|c|c|c|c|}
\hline & $\begin{array}{l}\text { Mean of } \\
\text { Study group } \\
(\mathrm{N}=30)\end{array}$ & $\begin{array}{l}\text { Mean of } \\
\text { Control group } \\
(\mathrm{N}=30)\end{array}$ & $\mathrm{X}^{2}$ & P-value \\
\hline $\mathrm{PH}$ & $7.34 \pm 0.36$ & $7.30 \pm 0.39$ & 1.996 & $.031 *$ \\
\hline $\mathrm{Pa} \mathrm{O} 2 / \mathrm{mmhg}$ & $92.03 \pm 3.40$ & $90.10 \pm 4.8$ & 6.097 & $.004 * *$ \\
\hline $\mathrm{Pa} \mathrm{Co} 2 / \mathrm{mmhg}$ & $46.2 \pm 6.70$ & $49.8 \pm 7.5$ & 2.979 & $.020^{*}$ \\
\hline $\mathrm{HCO} 3 / \mathrm{meq} / \mathrm{L}$ & $20.10 \pm 3.1$ & $19.3 \pm 2.6$ & 4.160 & $.013 *$ \\
\hline O2 sat (\%) & $96.11 \pm 4.1$ & $94.5 \pm 2.1$ & 5.999 & $.003 * *$ \\
\hline
\end{tabular}

Table (6) showed the Mean \& SD score of the ABGs test it was observed that the $\mathrm{PaO} 2$ level for the study group was (92.03 was \pm 3.40$)$ but it was $(90.10 \pm 4.8)$ for the control group also regarding the $\mathrm{O} 2$ saturation it was $(96.11 \pm 4.1)$ for the study group but it was $(94.5 \pm 2.1)$ for the control group. there was a statistically significant difference between the study and control group related to all items of the ABGs test presented by P-value with $\left(.031 *, .004 * *, .020^{*}, .013 * \& .003 * *\right)$.

\section{Discussion}

Cardiothoracic surgery is accompanying by pulmonary problems incidence, defined as any pulmonary abnormality that occurs during the postoperative period which creates detectable syndrome that is clinically important and affects the clinical course. Cardiothoracic surgery prompts severe postoperative pain and deficiency of pulmonary function, increases the length of stay (LOS) in hospital, and increases mortality and morbidity. Some thoracic physiotherapy techniques are used for respiratory function improvement in oxygenation and decline in respiratory complications (Vervoort, Meuris, et al, 2020).

Therefore the study aimed to assess evaluate the effect of immediate pain management on oxygenation level and among early extubated patients post-heart surgery. $P$ a g e | 100
Regarding demographic data, the current results revealed that the mean age of the study group was $38.4 \pm 5.4$ years, and the control group was $37.2 \pm 4.8$ years. As regard to gender and marital status, $56.7 \%$ and $76.7 \%$ of the study group were male and married, respectively and $63.3 \%$ and $73.3 \%$ of the control group were male and married, respectively. These results supported the study conducted by Kim, H. S., \& LaCamera, 2020 about the risk of the non-expandable lung following open-heart surgery, who reported that the mean age of the studied patient was $36.8 \pm 5.7$.

Concerning the educational level, the current results revealed that one-third of both groups had preparatory education. Moreover, about two-thirds of them were lived in rural areas. These results in cohort with the study performed by Elsaed, Mohamed \& Ebrahim, 2020 titled in Factors Mona S., et al 
Affecting Post Open-Heart Surgery Outcomes for Hospitalized Patients, who demonstrated that more than half of studied patients had a university education and residing in urban areas.

Regarding medical data, the current results presented that, more than one-third of the study group suffered from myocardial infarction and did coronary angioplasty surgery. and about one-third of the control group suffered from coronary artery stenosis and did coronary angioplasty surgery. These results agree with the study performed by Andonian et al., 2020 titled Assessment of the Psychological Situation in Adults with Congenital Heart Disease, who detected that more than one-third of studied patients undergoing coronary angioplasty.

Also, less than half and the majority of both groups suffered from physical inactivity and had a chronic disease. While about three-quarters and about two-thirds of the study group didn't have a history of cardiothoracic surgery and were not hospitalized previously. These results supported with the study performed by Pencina et al., 2019 titled in Quantifying Importance of Major Risk Factors for Coronary Heart Disease, who presented that chronic disease as HTN and DM affected coronary heart disease.

Related to mechanical ventilator parameters: The current results detected that there was no statistically significant difference between both groups of the study related to (Tidal volume, Fio2, Rate, PEEP, PS ....etc) at p-value $>0.05$. this result was taken before extubation of both groups of the study and it reflects the same mean parameters received by both groups of the study.

The current results revealed that the Mean \& SD of pain score for the study group at the 3rd day, 5th day and 7th day were $(6.76 \pm 1.05,5.04 \pm 1.30$ and $4.10 \pm 1.40$, respectively) but the control group was $(8.01 \pm 1.88,7.60 \pm 2.10$ and $5.42 \pm 1.50$, respectively) at the same period. Also, detected that there was a significant difference between the study and control group related to Pain score at $\mathrm{p}$-value $<0.05$.

These results were regular with the study performed by Yaban, 2020, about the usage of non-pharmacologic methods on postoperative pain management by nurses, who stated that the application of nonpharmacologic methods, known as pain controlling methods other than drugs, alone or in combination with pharmacologic methods is effective in decreasing the severity of pain, reducing the number of analgesics to be used, and decreasing the complication caused by strong analgesics such as opioids.

Also, in the same line with the study designed by Babatabar et al., 2020, titled in the effect of aromatherapy with rose and lavender on anxiety, surgical site pain, and extubation time after open-heart surgery, who detected that non-pharmacological pain management decline pain score and essences on reducing surgical site pain.I

These results were relevant to the study designed by Jayakumar, Borrelli, et al 2019 about Optimizing pain management protocols following cardiac surgery: A protocol for a national quality improvement study, which demonstrated that High levels of postoperative pain are associated with numerous consequences detrimental to recovery. Pain inhibits satisfactory coughing and deep breathing, and patients in pain breathe more rapidly and less deeply. High-levels of postoperative pain is associated with cardiovascular and respiratory complications.

Also, supported with the study done by RouhiBoroujeni, et al 2015 titled in Long-term pulmonary functional status following coronary artery bypass grafting surgery, who reported that a significant reduction is expected in most pulmonary functional parameters following CABG despite normal pulmonary function state preoperatively. Severe pain originated from sternotomy may be an important factor related to pulmonary dysfunction following CABG.

While another study found on the reverse with current study results, who represented that pain is known to be an unpleasant sensory and emotional experience associated with potential and actual tissue damage. Despite major advances in postoperative pain management, it continues to be a significant problem for many patients after major surgery. Pain following cardiac surgery is common, and, despite being largely avoidable, is moderate to severe in up to $75 \%$ of patients. Pain can prolong hospital stays and cause significant morbidity including psychological distress and in some cases, chronic pain (Choinière et al., 2014).

\section{Conclusion}

These results concluded that pain management measures were had a positive effect on the patient's breathing sound and arterial blood gases level which improves the patient's outcomes post-cardiac surgery.

\section{Recommendations}

- All cardiac surgery patients should receive an explanation about pain management strategies before their operations.

- $\quad$ Pain management strategies should be included as an important element in the protocol of care for cardiothoracic patients and emphasizing teaching for them during preoperative education.

- All cardiac intensive care unit nurses should receive an explanation about the nonpharmacological pain management measures based on evidence from researchers.

- Replication of the current research on a large probably samples with using other nonpharmacological pain management measures on cardiac surgery patients.

\section{References}

(1) Andonian, C., Beckmann, J., Ewert, P., Freilinger, S., Kaemmerer, H., Oberhoffer-Fritz, R., ... \& Neidenbach, R. (2020). Assessment of the Psychological Situation in Adults with Congenital Heart Disease. Journal of Clinical Medicine, 9(3), 779.

(2) Babatabar Darzi, H., Vahedian $\square$ Azimi, A., Ghasemi, S., Ebadi, A., Sathyapalan, T., \& Sahebkar, A. (2020). The effect of aromatherapy with rose and lavender on anxiety, surgical site pain, and extubation time after open $\square$ heart surgery: A doublec enter randomized controlled trial. Phytotherapy Research.

(3) Bjørnnes AK, Parry M, Lie I, Fagerland MW, Watt-Watson J, Rustøen T, et al. Pain experiences of men and women after cardiac surgery. J Clin Nurs 2016;25(19-20):3058-68 Cahalin LP, Lapier TK

(4) Choinière, M., Watt-Watson, J., Victor, J. C., Baskett, R. J., Bussières, J. S., Carrier, M., ... \& Racine, M. (2014). Prevalence of and risk factors for persistent postoperative nonanginal pain after cardiac surgery: a 2-year prospective multicentre study. Cmaj, 186(7), E213-E223.

(5) Elsaed, M. M., Mohamed, A. H., \& Ebrahim, M. N. (2020) Factors Affecting Post Open-Heart Surgery Outcomes for Hospitalized patients, Egyptian Journal of Health Care, 2020 Vol.11No.1.

(6) Gunay, S., Eser, I., Ozbey, M., Agar, M., Koruk, I., \& Kurkcuoglu, I. C. (2016). Evaluation of two different respiratory physiotherapy methods after thoracoscopy about arterial blood gas, respiratory function test, number of days until discharge, cost analysis, 
comfort, and pain control. Nigerian Journal of clinical practice, 19(3), 353-358.

(7) Jayakumar, S., Borrelli, M., Milan, Z., Kunst, G., \& Whitaker, D. (2019). Optimizing pain management protocols following cardiac surgery: A protocol for a national quality improvement study. International Journal of Surgery Protocols, 14, 1-8.

(8) Kim, H. S., \& LaCamera, P. (2020). Risk of Non-Expandable Lung Following Open-Heart Surgery. In A39. DIAGNOSIS AND TREATMENT IN PLEURAL DISEASE (pp. A1569-A1569). American Thoracic Society.

(9) Nair, S., \& Kazi, A. (2019). Efficacy of thoracic mobility and breathing exercises on chest expansion and pulmonary function values in post-intra-cardiac repair surgery patients. Journal of Pharmaceutical Sciences and Research, 11(10), 3458-3461.

(10) Oshvandi, K., Bostanbakhsh, A., Salavati, M., Bakhsai, M., Moghimbeighi, A., \& Maghsoudi, Z. (2020). Effect of Respiratory Exercises on the Prevalence of Atelectasis in Patients Undergoing Coronary Artery Bypass Surgery. Avicenna Journal of Nursing and Midwifery Care, 27(6), 432-440.

(11) Patman, S. (2019). Preoperative physiotherapy education prevented postoperative pulmonary complications following open upper abdominal surgery. BMJ evidence-based medicine, 24(2), 74-75.

(12) Pencina, M. J., Navar, A. M., Wojdyla, D., Sanchez, R. J., Khan, I., Elassal, J., ... \& Sniderman, A. D. (2019). Quantifying the importance of major risk factors for coronary heart disease. Circulation, 139(13), 1603-1611.
(13) Rouhi-Boroujeni, H., Rouhi-Boroujeni, H., Rouhi-Boroujeni, P., \& Sedehi, M. (2015). Long-term pulmonary functional status following coronary artery bypass grafting surgery. ARYA atherosclerosis, 11(2), 163-166.

(14) Vervoort, D., Meuris, B., Meyns, B., \& Verbrugghe, P. (2020). Global cardiac surgery: access to cardiac surgical care around the world. The Journal of thoracic and cardiovascular surgery, 159(3), 987-996.

(15) Xavier, G., Melo-Silva, C. A., Santos, C. E. V. G. D., \& Amado, V. M. (2019). Accuracy of chest auscultation in detecting abnormal respiratory mechanics in the immediate postoperative period after cardiac surgery. Jornal Brasileiro de Pneumologia, 45(5).

(16) Yaban, Z. S. (2019). Usage of Non-Pharmacologic Methods on Postoperative Pain Management by Nurses: Sample of Turkey. International Journal of Caring Sciences, 12(1), 529.

(17) Yazdannik, A., Bollbanabad, H. M., Mirmohammadsadeghi, M., \& Khalifezade, A. (2016). The effect of incentive spirometry on arterial blood gases after coronary artery bypass surgery (CABG). Iranian Journal of Nursing and Midwifery Research, 21(1), 89.

(18) Zanini, M., Nery, R. M., de Lima, J. B., Buhler, R. P., da Silveira, A. D., \& Stein, R. (2019). effects of different rehabilitation protocols in inpatient cardiac rehabilitation after coronary artery bypass graft surgery: a randomized clinical trial. Journal of Cardiopulmonary Rehabilitation and Prevention, 39(6), E19-E25. 